\title{
Different types of efficacy - what best predicts behavior?
}

\begin{abstract}
The current review presents a framework that maps the relative importance of self, collective, and means efficacies in predicting performance. It takes a new perspective on the ways these efficacies are grounded that aims to provide a better prediction of individuals' behavior than examinations of each efficacy separately. Specifically, individuals' beliefs in their internal abilities (self-efficacy) are expected to predict behavior because people have greater control over themselves than over external elements. However, external resources also impact behavior. Thus evaluations of collective efficacy, which involves relationships, should make an additional contribution to behavior beyond self-efficacy. Finally, beliefs in external material means in turn should make a contribution to predicting behavior over and above self and collective efficacies. Crucially, when introduced concurrently, this framework may be able to predict behavior based on the relative importance individuals assign to these efficacies. This model can thus lead to a much more comprehensive understanding of behavior because it takes the concurrent effects of internal and external resources into account when accounting for people's behavior. On a broader level, it may provide a richer grasp of the dynamics of individuals' evaluations of the efficacies that drive behavior.
\end{abstract}

Volume 9 Issue 4 - 2018

\author{
Erez Yaakobi \\ Department of Business Administration, Ono Academic College, \\ Israel
}

Correspondence: Erez Yaakobi, Senior lecturer, Department of Business Administration, Ono Academic College, Israel, Tel +(972)-50-9099567, Email dr.yaakobi@ono.ac.il

Received: July 29, 2018 | Published: August 06, 2018

\section{Introduction}

Bandura ${ }^{1}$ showed that the concept of self-efficacy, which he defined as individuals' beliefs in their abilities, could be a powerful predictor of improved performance. In fact, most empirical research have examined the ways self-efficacy predict and influence performance (e.g. see meta analyses of Haase et al., ${ }^{2}$ Miao et al. ${ }^{3}$ Sheeran et al., ${ }^{4}$ Talsma et al., ${ }^{5}$ ). However, according to Social Cognitive Theory, ${ }^{7}$ human agency manifests via interactions between three components: the person (e.g. thoughts and motivations), actions, and the context or setting in which they occur. Each component has a bidirectional influence on the others. Recent extensions to the conceptualization of efficacy, however, suggest that the construct of efficacy can be investigated not only as a self-referent perception about one's own capabilities, but also as an emergent property of the (social) system as a whole, which is called "collective efficacy". 7,8 Another external resource of efficacy is means efficacy, which is defined as individual's belief in the utility of external resources available for performing an action (e.g., tools, technology), which has been found to be an important complement to self-efficacy when predicting performance. ${ }^{9-12}$ These types of efficacies were grouped into internalexternal types of efficacies ${ }^{13}$ and findings tend to suggest that both components influence performance in separate, specific ways. ${ }^{9-14}$

Most empirical analyses have only examined the effects of only one component when predicting performance. However, no empirical examination of a framework to tease apart their concurrent impact on behavior has been put forward (with the exception of Yaakobi \& Wiesberg, ${ }^{12}$ which examined managers' beliefs in their employees and not employees themselves). Thus, since previous research has focused mainly on the internal component of efficacy beliefs (selfefficacy), and less on collective or means efficacy these studies may only provide an incomplete assessment of how efficacy influences behavior. A framework integrating people's beliefs in their internal and external resources concurrently should yield a much more comprehensive model and lead to a better understanding of the ways one's efficacies influence behavior.

\section{Self-efficacy}

The self-efficacy construct covers internal resources that people ascribe to themselves. It refers to peoples' beliefs that they are capable of carrying out an action to achieve a particular goal. ${ }^{7,15,16}$ Bandura $^{1}$, 2008) argued that self-efficacy plays an important role in determining the quality of one's performance. In Bandura's ${ }^{7}$ theory, self-efficacy in any context describes the belief in one's ability to perform in that context. He suggested that self-efficacy beliefs are conceived of as cognitive structures developed via interaction with the world. Bandura ${ }^{16}$ claimed that perceived self-efficacy influences behavior both directly as well as through its impact on one's goals, one's perception of socio-structural facilitators and impediments to one's behavior and one's outcome expectations. Adoption of habits are affected by one's pre-existing self-efficacy as well as external effects such as from the community which can influence changes in one's self efficacy through external messages affecting one's internal perceptions. There is vast empirical literature supporting the influence of greater self-efficacy on the investment of more resources, greater creativity, ${ }^{17-20}$ and the prediction of different performance facets such as innovativeness, efficiency as well as quality, ${ }^{12,21,22}$ better performance than those with lower self-efficacy both at work ${ }^{12}$ in educational setting ${ }^{23-25}$ and in terms of health behaviors. ${ }^{4,26-28}$

Although these studies provide some clues as to the nature of internal self-efficacy in resource allocation and performance, more recent studies have suggested that there appear to be external and not only internal aspects impacting people's beliefs in achieving success. ${ }^{9,12,29}$ Eden $^{13}$ defined collective and means efficacies as external efficacies, which refer to people's beliefs about available human or inanimate resources that are important to them for success; their presence or absence can help or hinder performance accordingly. These resources include equipment, tools, effective guidance or support, favorable working conditions, a superior starting point, or other facilitators. ${ }^{13}$ External efficacy can also be composed of the capacities of the group one belongs to, the availability of means, and/ or the circumstances. Individuals conduct tasks solely as well as in 
groups and teams. When conducting tasks in teams or even when conducting a task alone but when people may need help from others, the belief in other's accessibility and ability to accomplish a task is likely to come into action in one's mind.

\section{Collective efficacy}

Collective efficacy covers the individual's beliefs in the ability of his or her team or unit to successfully carry out the duties assigned to them effectively. ${ }^{13}$ Studies have shown that greater collective efficacy was associated with fewer errors in nursing care. ${ }^{30}$ Collective efficacy was also positively linked to people's evaluations of their innovative performance ${ }^{31}$ and actual innovativeness ${ }^{32}$ and their quality of decision making. ${ }^{33}$ Collective efficacy also mediated the relationship between ability-enhancing practices and team creativity. ${ }^{34}$ A meta-analytic review reported a strong positive relationship between collective efficacy and group performance. ${ }^{35}$ Studies $^{36}$ on group cohesion (i.e. team members' positive feelings about group interaction) were found to be highly correlated with collective efficacy and positively predicted performance in teams. ${ }^{37-40}$ There is empirical evidence demonstrating the influence of collective efficacy on group processes (e.g. goal setting, task strategies employed) and outcomes such as task performance. ${ }^{7,41-43}$

In line with the Social Cognitive theory perspective, Ozyilmaz et al. ${ }^{44}$ contended that an employees' trust in themselves or selfefficacy, should interact with individuals' trust in the system, or trust in organization, to predict job attitudes and behaviors. Their results confirmed these claims. Specifically, self-efficacy had more positive effects on job satisfaction, task performance, and citizenship behaviors when trust in the organization was high. Moreover, self-efficacy had a positive effect on turnover intentions when trust in organization was low. They suggested that high trust in organization buffered the effects of self-efficacy on intentions to leave. They concluded that the motivational value of trust in oneself is stronger to the extent to which employees also have high trust in the system, whereas low trust in the system neutralizes the motivational benefits of self-efficacy.

The antecedents of collective efficacy may also depend on the role of enactive mastery, where confidence builds up over time as groups receive feedback about their performance on a task, as well as through vicarious experience and verbal persuasion. ${ }^{8,16,45,46}$ Recently ${ }^{47}$ examined individual efficacy in teams to better understand how the interaction between individual self-concept and the context influences individual performance and creativity. Drawing on Social Cognitive theory, the authors showed that achieving the best performance and creative results is not about more of each type. When individuals are low on self-efficacy, team climates encouraging exploitation and exploration deliver increasing performance and creative benefits. The situation is more complex for efficacious individuals. Up to moderate levels of team encouragement, exploitation and exploration are associated with clear performance and creative returns. However, when team encouragement of exploitation and exploration increases beyond this point, the returns on such encouragement diminish and individuals with high levels of self-efficacy show less additional performance and creative returns. These results hint that the integrative effects of efficacies may better account for performance.

\section{Means efficacy}

Means efficacy is the individual's belief in the aggregate subjective utility of the means or tools available for a task ${ }^{13}$ such as machinery, money, information and time. Eden suggested that because means efficacy is as motivating as self-efficacy, a high level of belief in the efficacy of available means may encourage a person to use these means to a greater extent. Individuals ascribe a utility value to means or tools that can facilitate or hamper their performance. Thus, means exist independently of individuals' ability, and belief in the means is different from belief in the self. ${ }^{9}$ The perception of available tools as modern, efficient, well-maintained and appropriate for conducting a task increases a person's confidence in being able to accomplish them. Diminished belief in the efficacy of the tools is frustrating and demoralizing, since inadequate means can neutralize even abundant internal resources. Means efficacy is related to the nature of a given task and how individuals perceive these resources as contributing to or impeding effective performance. ${ }^{10}$ There is empirical evidence for a positive influence of means efficacy in predicting performance. ${ }^{11,48}$ It has been also shown that externally augmenting individuals' beliefs in their means can improve their performance. ${ }^{9,49}$ An interaction between means efficacy and self-efficacy was found empirically where higher levels of both self-efficacy and means efficacy resulted in the highest levels of supervisor ratings of task performance. ${ }^{11}$ This empirical evidence calls for a broader empirical examination of the interactions not only between self-efficacy and collective efficacy or means efficacy but rather the three-way interactions between self, collective and means efficacies. In addition, the findings suggest the value of exploring whether collective and means efficacies have an additive influence on people's performance or whether one efficacy compensates for the other.

\section{A new efficacy model framework}

As suggested by the Internal-External Efficacy model, selfefficacy is an insufficient explanation for self-regulated behavior because it ignores the influence of external resources. ${ }^{29} \mathrm{~A}$ recent study of managers' perceptions of their employees' resources showed that internal resources (i.e. self-efficacy) had the highest weight in predicting employees' performance followed by collective and means efficacy. ${ }^{12}$ However, it still remains unclear how the weights ascribed by individuals to different efficacies best predict their performance and more generally their behavior. These gaps in empirical knowledge calls for additional empirical work on the relative importance of these different efficacies as perceived by the individual. Since people have more control over internal than external resources people may ascribe more weight to the self than to collective or means efficacy. However, personality dimensions should also moderate the weights attributed to the different efficacies. For example, based on the well-known Big five model of personality ${ }^{50}$ it is suggested that more neurotic individuals are likely to give self-efficacy less weight than to collective and means efficacies and vice-versa.

The internal-eternal efficacy model relates to self-efficacy as an internal resource and defines collective and means efficacies as external resources. However, these efficacies can be also categorized in terms of inner beliefs of the individual relating to the self (selfefficacy), internal beliefs relating to the person's ability to interact with others, as well as others' willingness to provide the sufficient resources him or her. Thus, collective efficacy can be perceived as both an internal and an external resource. This also calls for an empirical examination of the ways different individuals perceive the notion of collective efficacy.

Another way of framing the differences between the three types of efficacies are in terms of more human-like mechanisms (self 
and collective efficacies) vs. non-human-like resources (i.e. means efficacy). Here, future empirical work should examine which model best corresponds to Banduras' efficacy model. One possible way to investigate this would be by examining personality variables such as the big five $e^{50}$ to see which are more closely related to each type of efficacy. In a recent meta-analysis, Stajkovic et al. ${ }^{51}$ tested three conceptual models of the influence of the big five personality traits and self-efficacy on academic performance. They found that self-efficacy positively related to academic performance across the models, conscientiousness and emotional stability were predictive of self-efficacy and performance in some analyses, but that the impact of the other three traits was negligible. It is important to examine this model using collective and means efficacies and to test these predictions on other domains than academia. This may help identify which personality variables are associated with performance and thus contribute to the conceptualization of the different efficacies into their human vs. non-human features. For example, agreeableness, which is related to behaviors and preferences for interactions with others, warmth and collaboration ${ }^{50}$ is expected to be related to collective efficacy if collective efficacy is seen as related to the division into human vs. non-human. However, if the internal/ external division is more appropriate, agreeableness should not be as highly related to collective efficacy and neuroticism should come into play. These personality dimensions could help better identify the grounding of the efficacy dimensions. The suggested model is presented in Figure 1.

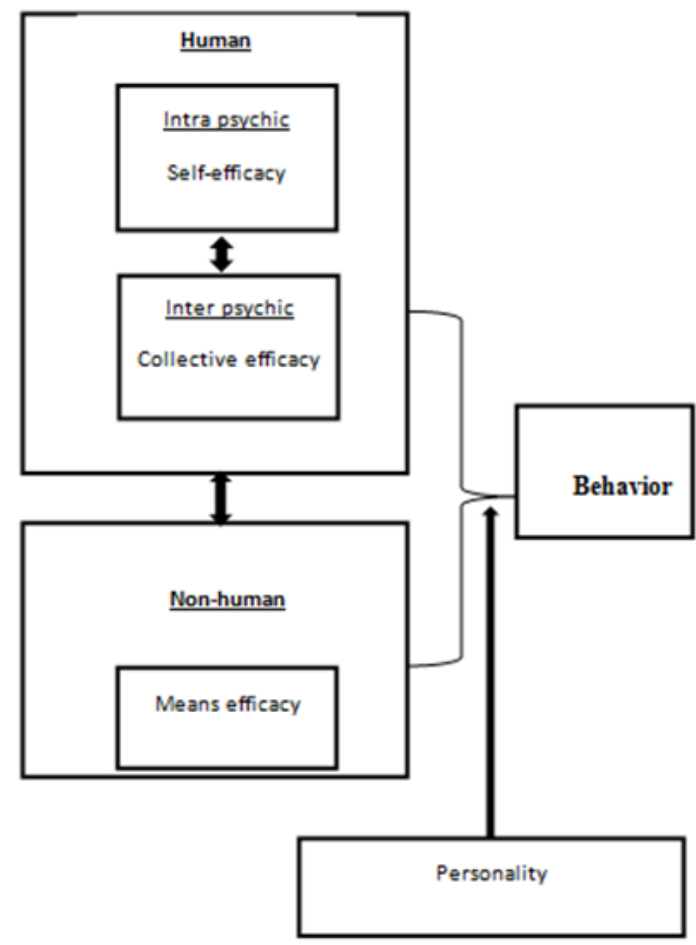

Figure I A model of self, collective and means efficacies in predicting behavior.

Empirically examining this model can lead to a much more comprehensive understanding of behavior because it takes the concurrent effects of various internal and external resources into account when explaining people's behavior. It could also help evaluate the relative importance people ascribe to the different levels. Identifying the core of each efficacy could facilitate ways to promote efficacy beliefs by emphasizing these elements. Overall, this model should lead to a richer grasp of the dynamics of individuals' evaluations of efficacies when accounting for behavior

\section{Acknowledgement}

None.

\section{Conflict of interest}

The author declares that there is no conflict of interest.

\section{References}

1. Bandura A. Self-efficacy: Toward a unifying theory of behavioral change. Psychological Review. 1977;84(2):191-215.

2. Haase J, Hoff EV, Hanel PHP, et al. A meta-analysis of the relation between creative self-efficacyand different creativity measurements. Creativity Research Journal. 2018;30(1):1-16.

3. Miao C, Qian S, Ma D. The relationship between entrepreneurial selfefficacy and firm performance: A meta-analysis of main and moderator effects. Journal of Small Business Management. 2017;55(1):87-107.

4. Sheeran P, Maki A, Montanaro E, et al. The impact of changing attitudes, norms, and self-efficacy on health-related intentions and behavior: A metaanalysis. Health Psychol. 2016;35(11):1178-1188.

5. Talsma K, Schüz B, Schwarzer R, et al. I believe, therefore I achieve (and vice versa): A meta-analytic cross-lagged panel analysis of selfefficacy and academic performance. Learning and Individual Differences. 2018;61:136-150

6. Bandura A. Social foundations of thought and action: A social cognitive theory. Englewood Cliffs, NJ: Prentice-Hall; 1986.

7. Bandura A. Self-efficacy: The exercise of control. New York, NY: W H Freeman/Times Books/Henry Holt \& Co; 1997.

8. Gibson CB, Earley PC. Collective cognition in action: Accumulation interaction, examination, and accommodation in the development and operation of group efficacy beliefs in the workplace. The Academy of Management Review. 2007;32(2):438-458.

9. Eden D, Ganzach Y, Granat-Flomin R. Augmenting means efficacy to improve performance: Two field experiments. Journal of Management. 2010;36(3):687-713.

10. Eden D, Sulimani R. Pygmalion training made effective: Greater mastery through augmentation of self-efficacy and means efficacy. In: Avolio BJ, Yammarino FJ, editors. Transformational/charismatic leadership: The road ahead. New York: Elsevier; 2002.

11. Walumbwa FO, Avolio BJ, Zhu W. How transformational leadership weaves its influence on individual job performance: The role of identification and efficacy beliefs. Personnel Psychology. $2008 ; 61(4): 793-825$.

12. Yaakobi E, Weisberg J. Individual, group and organizational efficacies in predicting performance. Personnel Review. 2018;47(2):535-554.

13. Eden D. Means efficacy: External sources of general and specific subjective efficacy. In: Erez M, Kleinbeck U, Thierry H. editors. Work motivation in the context of a globalizing economy. Mahwah, NJ: Lawrence Erlbaum; 2001:73-85.

14. McNatt BD, Judge TA. Self-efficacy intervention, job attitudes, and turnover: A field experiment with employees in role transition. Human Relations. 2008;61(6):783-810.

15. Bandura A. Perceived self-efficacy in cognitive development and functioning. Educational Psychologist. 1993;28(2):117-148.

16. Bandura A. Health Promotion by Social Cognitive Means. Health Educ Behav. 2004;31(2):143-164 
17. Jaiswal NJ, Dhar RL. Transformational leadership, innovation climate, creative self-efficacy and employee creativity: A multilevel study. International Journal of Hospitality Management. 2015;51:30-41.

18. Jaussi KS, Randel AE. Where to look? Creative self-efficacy, knowledge retrieval, and incremental and radical creativity. Creativity Research Journal. 2014;26(4):400-410.

19. Puente-Diaz R, Arroyo JC. An exploration of some antecedents and consequences of creative self-efficacy: The role of achievement goals, enjoyment and divergent thinking. Creativity. Theories- ResearchApplications. 2016;3:19-33.

20. Rego A, Sousa F, Marques C, et al. Retail employees' self-efficacy and hope predicting their positive affect and creativity. European Journal of Work and Organizational Psychology. 2012;21(6):923-945.

21. Bhanthumnavin D. Perceived social support from supervisor and group members' psychological and situational characteristics as predictors of subordinate performance in Thai work units. Human Resource Development Quarterly. 2003;14(1):79-97.

22. Ritchie L, Williamon A. Self-efficacy as a predictor of musical performance quality. Psychology of Aesthetics, Creativity, and the Arts. 2012;6(4):334-340.

23. Lee W, Lee MJ, Bong M. Testing interest and self-efficacy as predictors of academic self-regulation and achievement. Contemporary Educational Psychology. 2014;39(2):86-99.

24. Schunk DH, Di Benedetto MK. Self-efficacy: education aspects. In: Wright JD, editor. International Encyclopaedia of the Social \& Behavioral Sciences. $2^{\text {nd }}$ edition, Oxford: Elsevier; 2015:515-521.

25. Mastenbroek NJJM, Jaarsma ADC, Scherpbier AJJA. The role of personal resources in explaining well-being and performance: A study among young veterinary professionals. European Journal of Work and Organizational Psychology. 2014;23(2):190-202.

26. Bandura A. Psychological aspects of prognostic judgments. In R. W. Evans, DS Baskin, \& FM Yatsu editors. Prognosis of Neurological Disorders. $2^{\text {nd }}$ edition, New York: Oxford University Press;2000:11-27.

27. Holman H, Lorig K. Perceived self-efficacy in self-management of chronic disease. In R Schwarzer editor. Self-Efficacy: Thought Control of Action. Washington, DC, Hemisphere; 1992:205-323.

28. Rimal RN. Closing the knowledge-behavior gap in health promotion: The mediating role of self-efficacy. Health Commun. 2000;12(3):219-237.

29. Simmons AL, Payne SC, Pariyothorn MM. The role of means efficacy when predicting creative performance. Creativity Research Journal. 2014;26(1):53-61.

30. Lee TW, Ko YK. Effects of self-efficacy, affectivity and collective efficacy on nursing performance of hospital nurses. J Adv Nurs. 2010;66(4):839-848.

31. Salanova M, Lorente L, Martinez IM. The dark and bright sides of selfefficacy in predicting learning, innovative and risky performances. The Spanish Journal of Psychology. 2012;15(3):1123-1132.

32. Choi JN, Chang JY. Innovation implementation in the public sector: an integration of institutional and collective dynamics. J Appl Psychol. 2009;94(1):245-253.

33. Lam SSK, Schaubroeck J. Information sharing and group efficacy influences on communication and decision quality. Asia Pacific Journal of Management. 2011;28(3):509-528.

34. Ma Z, Long L, Zhang Yl. Why do high-performance human resource practices matter for team creativity? The mediating role of collective efficacy and knowledge sharing. Asia Pacific Journal of Management. 2017;34:565-586.
35. Stajkovic AD, Lee D, Nyberg AJ. Collective efficacy, group potency, and group performance: Meta-analyses of their relationships, and test of a mediation model. J Appl Psychol. 2009;94:814-828.

36. Lee C, Farh JL. Joint effects of group efficacy and gender diversity on group cohesion and performance. Applied Psychology. 2004;53:136-154.

37. Casey-Campbell M, Martens ML. Sticking it all together: A critical assessment of the group cohesion-performance literature. International Journal of Management Reviews. 2009;11(2):223-246.

38. Castaño N, Watts T, Tekleab AG. A reexamination of the cohesionperformance relationship meta-analyses: A comprehensive approach. Group Dynamics: Theory Research and Practice. 2013;17(4):207-231.

39. Lent RW, Schmidt J, Schmidt L. Collective efficacy beliefs in student work teams: Relation to self-efficacy, cohesion, and performance. Journal of Vocational Behavior. 2006;68(1):73-84.

40. Klassen RM, Usher EL, Bong M. Teachers' collective efficacy, job satisfaction, and job stress in cross-cultural context. The Journal of Experimental Education. 2010;78(4):464-486.

41. Katz-Navon TY, Erez M. When Collective and Self-Efficacy Affect Team Performance: The Role of Task Interdependence. Small Group Research. 2005;36(4):437-465.

42. Khong JZN, Liem GAD, Klassen RM. Task performance in small group settings: The role of group members' self-efficacy and collective efficacy and group's characteristics. Educational Psychology. 2017;37(9):1082-1105.

43. Kellett JB, Humphrey RH, Sleeth RG. Career development, collective efficacy, and individual task performance. The Career Development International. 2009;14(6):534-546.

44. Ozyilmaz A, Erdogan, B, Karaeminogullari, A. Trust in organization as a moderator of the relationship between self-efficacy and workplace outcomes: A social cognitive theory-based examination. Journal of Occupational and Organizational Psychology. 2018;91(1):181-204.

45. Lester SW, Meglino BM, Korsgaard MA. The antecedents and consequences of group potency: A longitudinal investigation of newly formed work groups. Academy of Management Journal. 2002;45(2):352-368.

46. Tasa K, Taggar S, Seijts GH. The development of collective efficacy in teams: A multilevel and longitudinal perspective. J Appl Psychol. 2017;92(1):7-27.

47. Hirst G, van Knippenberg D, Zhou Q, et al. Exploitation and exploration climates' influence on performance and creativity: Diminishing returns as function of self-efficacy. Journal of Management. 2018;44(3):870-891.

48. Hannah ST, Avolio BJ, Walumbwa FO, et al. Leader Self and Means Efficacy: A multi-component approach. Organizational Behavior and Human Decision Processes. 2012;118(2):143-161.

49. Chen S, Westman M, Eden D. Impact of enhanced resources on anticipatory stress and adjustment to new technology: A field-experimental test of conservation of resource theory. Paper presented at the Work, Stress and Health 2006: Making a Difference in the Workplace conference, Miami, FL; 2006.

50. Costa PT, McCrae RR. Revised NEO personality inventory and NEO five factor inventory. Odessa, FL: Psychological Assessment Services; 1992.

51. Stajkovic AD, Bandura A, Locke EA, et al. Test of three conceptual models of influence of the big five personality traits and self-efficacy on academic performance: A meta-analytic path-analysis. Personality and Individual Differences. 2018;120:238-245. 